\title{
SINDROME DE WEST EM GÊMEOS UNIVITELINOS
}

\author{
EDSON ZERATI* - ANTONIO SEBA JUNIOR*
}

\begin{abstract}
RESUMO - Os autores registram os casos de dois gêmeos univitelinos com 6 meses de idade, do sexo masculino, com quadro de espasmos em flexão. $O$ EEG nas duas crianças é idêntico, mostrando hipsarritmia. Foi empregado ACTH (2 unidades/K/dia) durante três semanas, com boa resposta ao medicamento. As crises cessaram no terceiro dia de administraç̃o do ACTH. Atualmente, o tratamento de manutenção é feito com clonazepam.
\end{abstract}

\section{West syndrome in identical twins.}

SUMMARY - The authors report the cases of two identical male twins, 6 months old, with flection spasms. Their EEG vere identical, and showed hipsarrhythmia. ACTH was used in daily doses of 2 units during three weeks, and both patients responded well. The spasms ceased three days after beginning treatment with ACTH. At present, treatment is continued with clonazepam.

É rara a observação da ocorrência da síndrome de West em gêmeos univitelinos. $\mathrm{O}$ fato de termos observado a síndrome em dois irmãos, gêmeos univitelinos, motivou o presente registro.

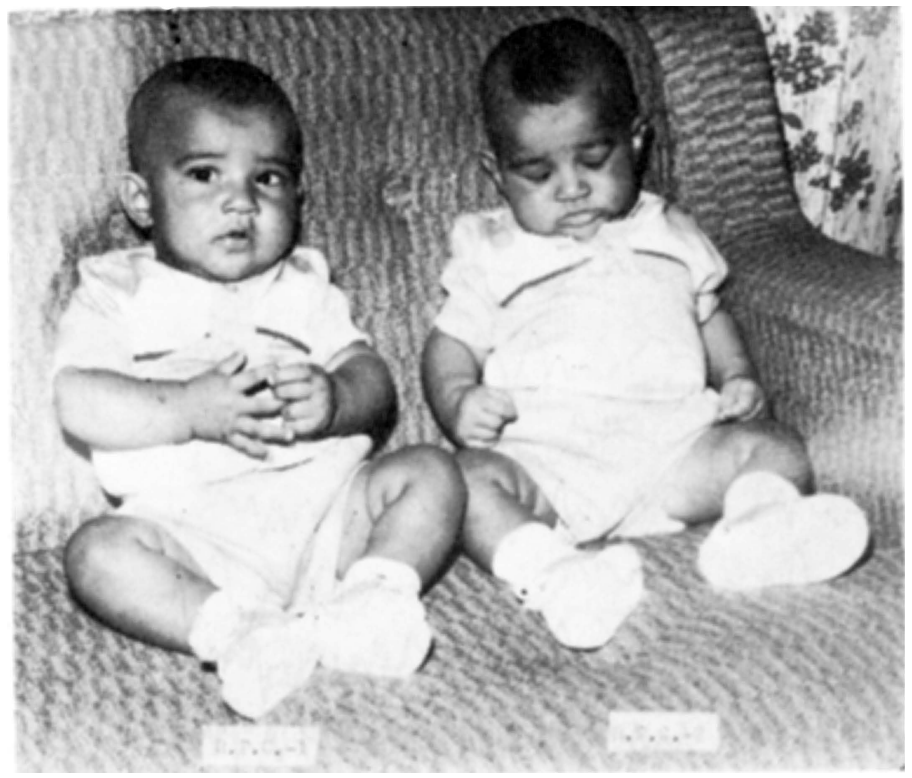

Fig. 1 - Aspectos dos gêmeos univitelinas que apresentam a sindrome de West (RPC-1 $e$ $R P(-2)$.

* Serviço de Neurologia da Santa Casa de Misericórdia de Votuporanga. Dr. Edson Zerati —Rua Santa Catarina 187 - 15500 Votuporanga SP - Brasil. 


\section{OBSEKVAÇŌES}

RPC-1 e RPC-2 șão dois irmảos gêmeos linivitelinos do sexo masculino, nascidos de parto cesariano, pré-termos, 32 semanss de gravidez, sem anóxia neonatal ou quaisquer intercorrências. Apgar (6-9 e 7-9), pesos (1940 e 1980 g) e alturas (41 e 42 cm) correspondentes. Alta com 23 dias de vida. Gestaçāo sem intercorrências, exceto trabalho de parto prematuro. Apresentaram bom ganho pôndero-estatural, recebendo aleitamento artificial $\theta$ suplementaçăo vitamínica. Nos controles notava-se discreto atraso neuromotor compativel a prematuridade e estrabismo convergente, não fixo, desde o 10 mês vida (Fig. 1). Aos 6 meses surgiram crises em ambas as criancas, praticamente no mesmo dia, caracterizadas por episódios de flex̄̄o dos membros superiores, membros inferiores, tronco e segmento cefálico, com hipertonia generalizada e desvio ocular, com duração de cerca de 3 minutos. Algumas vezes, sonolência vosterior à crise. Ao exame neurolónico (70 mês) notava-se, em anıbos, retardo neuromotor conı débil sustentacăo do segmenț cefálico, hipotonia genera-

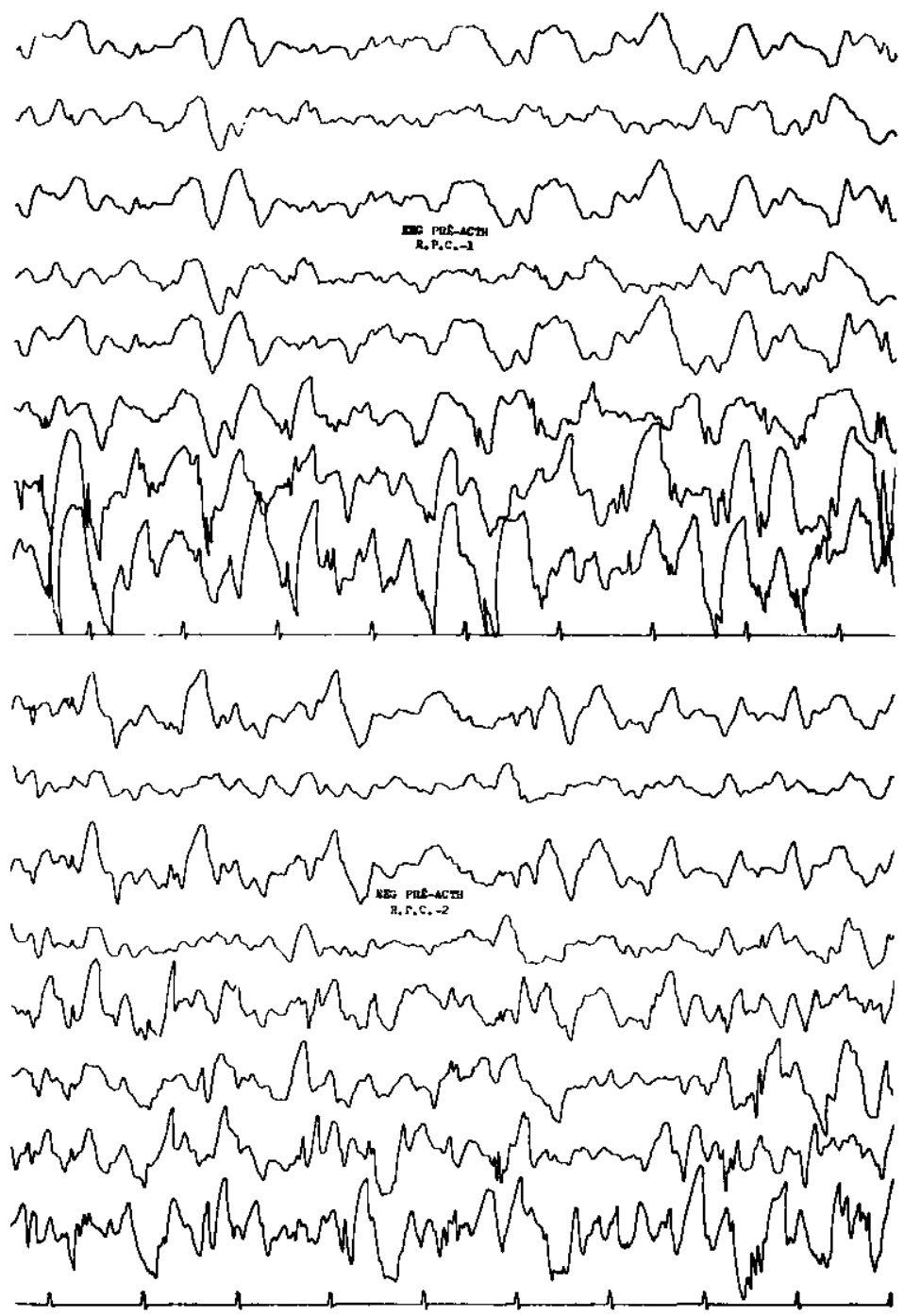

Fig. 2 - EEG antes do ACTH. Em cima,gêmeo RPC-1. Em baixo, gêmeo RPC-2. Hipsarritmia ondas arritmicas $e$ difusas, com algumas pontas intercaladas, assincronas. 
lizada, reflexo de Moro ausente e estrabismo convergente fixo e bilateral. $O$ restante do exame foi normal, inclusive perimetro cefálico (41 cm). Felto eletrencefalograma (EEG), constatou-se hipsarritmia em ambas as criancas (Fig. 2). Fol introduzido ACTH na dosagem de 2 unidades/Kg/dia, mantido por três semanas. As crises cessaram no terceiro dia de administração do ACTH. Feito novo EEG após o período de tratamento, o traçado já estava normalizado (Fig. 3). Nessa fase foi introduzido o clonazepam. Atualmente, as criancas estäo bem e sem críses. O liquido cefalorraquidiano e a tomografia computadorizada do cránio foram normais nos dois pacientes.

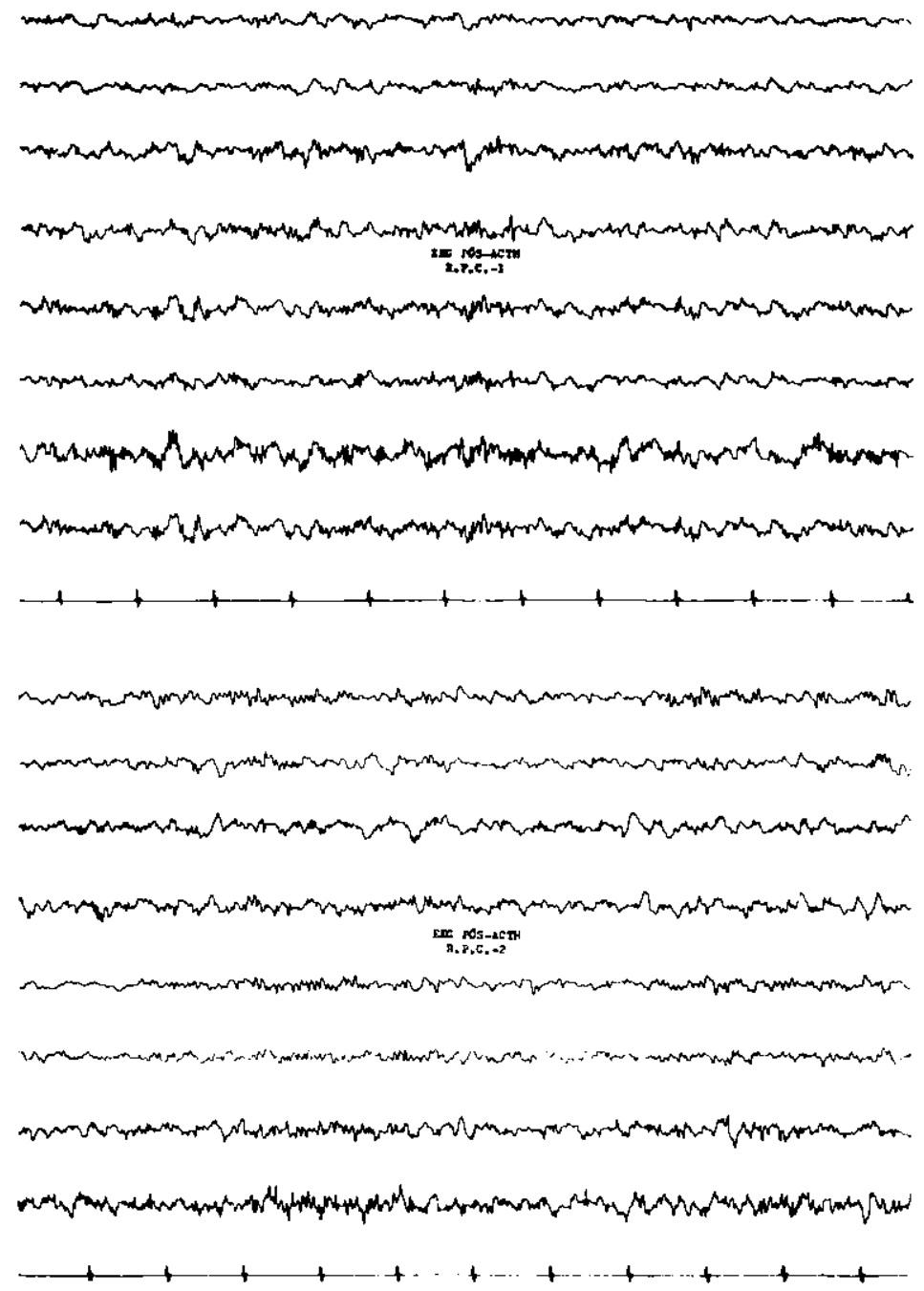

Fig. s- EEG ap6s o ACTH. Em cima, gêmeo RPC-1. Em baixo, gemeo RPC-2. Trasado praticamente normalizado.

\section{COMENTARIOS}

Em 1841, West 5 descreveu uma forma peculiar de convulsão infantil associada a retardo mental. Vasques e Turner 4 , em 1951, publicaram artigo no qual descreveram a sindrome, com suas características clinicas e eletrencefalográficas. Gibbs e Gibbs 2 , em 1952, utilizaram o termo hipsarritmia para caracterizar a síndrome. 
Gastaut e col. calculam que, na França, a síndrome ocorre em $2,4 \%$ de todos os casos de epilepsia 1. Quanto ao sexo, os autores sāo unânimes em afirmar 1 que ocorre mais no sexo masculino, na proporção de $2: 1$. A patologia mais frequentemente relacionada à sindrome é a encefalopatia perinatal $(22-48 \%)$. Em $70 \%$ dos casos ocorre o espasmo em flexão. O EEG consiste de sucessão ininterrupta de ondas lentas e rápidas, de amplitude extremamente grande, bilaterais, difusas e assíncronas 1. É importante realizar o diagnóstico adequado precocemente e introduzir, de imediato, tratamento com ACTH para evitar uma encefalopatia mais grave (retardo mental severo e crises tônico-clônicas) 1 .

O diagnóstico só poderá ser considerado definitivo se o EEG mostrar a anomalia específica 3 . Nos casos aqui relatados, a natureza idiopática do processo é a mais provável, devendo ser ressaltada a raridade da ocorrência da síndrome em gêmeos univitelinos.

\section{REF'ERENCIAS}

1. Gastaut H, Broughton R - Ataques Epilépticos. Toray, Barcelona, 1975.

2. Gibbs FA, Gibbs EL - Atlas of Electroencephalography, Voi 2. Adison-Wesley, Cambridge, 1952.

3. Lelèvre AB, Diament AJ - Neurologia Infantil. Sarvier, São Paulo, 1980.

4. Vasques H.J, Turner $\mathbf{M}$ - Epilepsia en flexión generalizada. Arch Argent Pediat 35:111, 1951.

5. West H.J - On a Deculiar form of infantile convulsions. Lancet 1:724, 1841. 